\title{
The impact of COVID-19 response measures on the quality of life for children in the Eastern Mediterranean region using an exposome approach: a narrative review
}

\author{
Nadine Haddad', Hala Abou Naja ${ }^{2}$, Konstantinos C. Makris ${ }^{3} \otimes$ \\ 1 Water and Health Laboratory, Cyprus International Institute for Environmental and Public Health, School of Health Sciences, Cyprus University of \\ Technology, Cyprus; Epidemiological Surveillance Program, Lebanese Ministry of Public Health, Beirut, Lebanon, 2 Epidemiological Surveillance \\ Program, Lebanese Ministry of Public Health, Beirut, Lebanon, ${ }^{3}$ Water and Health Laboratory, Cyprus International Institute for Environmental and \\ Public Health, School of Health Sciences, Cyprus University of Technology, Cyprus \\ Keywords: lockdown, children, non-pharmacological interventions, exposome, covid-19 \\ https://doi.org/10.29392/001c.25469
}

\section{Journal of Global Health Reports}

Vol. 5, 2021

\begin{abstract}
Background
There is a consensus that children's needs have not been sufficiently prioritized during the COVID-19 pandemic, and their right to a safe and healthy childhood has been compromised to an extent, worldwide. A comprehensive assessment of population- and individual-level changes associated with COVID-19 and its pandemic response measures could be undertaken using the human exposome concept. The exposome is defined as the totality of environmental exposures from conception onwards, including the endogenous response. The objective of this study was to conduct a narrative review using an exposome approach exploring short-term changes in the children's exposome profile $(<18$ years old) associated with the COVID-19 measures implemented in the Eastern Mediterranean region (EMR).
\end{abstract}

\section{Methods}

Google Scholar, PubMed and Reliefweb databases were searched for original studies and situation reports published in English between January 1, 2020 and January 31, 2021, pertinent to the EMR countries. Publications describing a quantitative or qualitative impact of the COVID-19 pandemic measures on children were summarized using the three exposome domains: general external (policies and programs), specific external (lifestyle and environmental contaminants) and internal (intrinsic properties, metabolism, etc.).

\section{Results}

Out of 405 results generated from PubMed and Google Scholar and 687 reports identified from Reliefweb, a total of 16 original research articles and 36 situation reports were retained, involving 14 out of 22 EMR countries. Most publications documented the impact of COVID-19 pandemic measures on children's general and specific external exposome domains, while few studies dealt with the internal domain (risk of stunting, malnutrition). In effect, chronic efforts by national and international programs to tackle historical EMR challenges of child protection from labor, displacement, trauma and violence, promotion of education, and eradication of pediatric malnutrition and infectious diseases seem to be at risk during the COVID-19 crisis, either due to inaction or suspension of children's services and programs.

\section{Conclusions}

Regional authorities and governmental bodies are pledged to assess the impact of the wider array of COVID-19 response measures on children's exposome profile. A prompt deployment of multi-sectoral COVID-19 recovery plans is warranted for the benefit of the children in the EMR region.

The novel coronavirus disease (COVID-19) pandemic response is ongoing via the deployment of a series of nonpharmacological interventions (NPIs) aiming to flatten the curve and break disease transmission chains, worldwide. The implemented NPIs part of the COVID-19 response range from mobility and gathering restrictions to closures 
of educational, recreational, workplace and religious entities, affecting the daily lives of billions around the world and, thus, altering people's lifestyle and behavioral routine, including their exposures to a suite of environmental determinants of disease.

The utility of the human exposome concept in holistically characterizing changes in population-level and individual-level exposures ensued by COVID-19 and its associated NPIs was recently put forward. ${ }^{1}$ The human exposome, initially proposed by Dr Christopher Wild in 2005, encompasses life-course environmental exposures that are dynamically changing from the prenatal period onwards, complementing the genome. ${ }^{2}$ Three exposome domains, often overlapping, are used to classify these environmental exposures: the general external domain, encompassing wider social influential factors (such as programs and policies, social capital, education, financial status, psychological and mental stress); the specific external domain, comprising personal exposures to chemical contaminants, physical stressors, infectious agents, lifestyle factors, etc.; and the internal exposome domain, which comprises elements of the endogenous response and individual features, such as body morphology, endogenous response to external stimuli, external chemicals, drugs, metabolites, etc. ${ }^{2,3}$ The COVID-19 pandemic and its NPIs are anticipated having a combined effect on the exposome; on one hand, the severe acute respiratory syndrome coronavirus 2 (SARS-CoV-2) pathogen is in itself a novel environmental agent affecting infectious disease risk and, on the other hand, the associated NPIs impacted either directly or indirectly the urban exposome profile of various (sub)population groups living in the city. ${ }^{1}$

After a year in the pandemic, children's population $(<18$ years old) have been shown with milder clinical signs and symptoms, while recording the lowest attack and case-fatality rates when compared with those of older age groups. ${ }^{4-6}$ Nevertheless, repercussions of the COVID-19 associated NPIs on the physical, psychosocial and mental well-being of children were showcased in various studies around the globe. ${ }^{7-9}$ Amidst the ongoing challenges to ensure a safe and healthy childhood, a WHO-UNICEF-Lancet Commission initiative was announced; the so-called Children in All Policies 2030 aims to center children's health and wellbeing in the overall activities of sustainable development goals. 10

On a global scale, there is a consensus that children's needs have not been sufficiently prioritized during the COVID-19 pandemic. Children of lower- and middle-income countries appear to be mostly affected by the repercussions of the COVID-19 and its accompanying NPI measures. ${ }^{8}$ A special attention was drawn to the Eastern Mediterranean region (EMR), home to approximately 25 million children of marginalized groups, such as refugees, migrants and internally displaced families often living in suboptimal conditions with a pre-existing fragile access to basic services and in need of humanitarian assistance. ${ }^{11,12}$ It is noteworthy mentioning that the COVID-19 pandemic and its associated NPI measures have weakened or disrupted the provision of basic community services in the EMR region that approximately hosts $64 \%$ of the global population of refugees and one third of the world's inter- nally displaced population. ${ }^{13,14}$ Consequently, governments and other operating agencies are called upon to respond to this unprecedented crisis by scaling up their efforts towards a reliable provision of essential educational, nutritional, health and child protection services.

Studies of COVID-19 impacts on children's well-being and quality of life are warranted to better inform COVID-19 recovery and action plans for the EMR region. Before COVID-19, the EMR region was historically a region of recurring events of wars, natural disasters and political crises that acted as overwhelming obstacles against efforts to safeguarding children's health. Thus, we embarked on a narrative review investigating short-term changes in the children's exposome profile ( $<18$ years old) associated with the NPI measures that were implemented in the EMR region from January 2020 to end of January 2021.

\section{METHODS}

A series of NPI measures were implemented in mid-March 2020 for most of the EMR countries, including travel bans, movement and gathering restriction, closure of non-essential business and schools and eventually the implementation of a nationwide lockdown; these measures continued in the following months with variable stringency and intensity/duration. ${ }^{15,16}$ Our population of interest was children below 18 years old as defined by the United Nations Convention on the Rights of the Child. ${ }^{17}$

For our narrative review, three search engines were included and search strings were implemented between $1^{\text {st }}$ and $11^{\text {th }}$ February 2021: PubMed, Google Scholar and Reliefweb "www.reliefweb.int", i.e., the humanitarian information portal administered by the United Nations Office for the Coordination of Humanitarian Affairs (OCHA). The OCHA portal provides daily updates issued by the United Nations System, governments and inter-governmental organizations on the status of global crisis and disasters. ${ }^{18}$ Original research articles and situation reports published in English between January $1^{\text {st }} 2020$ and January $31^{\text {st }} 2021$, containing in-text the words (COVID AND child\$), pertinent to any of the EMR countries were initially selected and screened by two researchers. Publications retained from PubMed and Google Scholar were first screened jointly by title to remove duplicates, then by abstracts to exclude editorials and commentaries. Excluded studies were also those describing epidemiological, clinical characteristics and case management of COVID-19 infection in children, as well as studies not tackling the effect of the NPIs on children. In parallel, the situation reports selected from Reliefweb were screened to exclude those describing the COVID-19 epidemiological overview; tackling events other than COVID-19 pandemic such as armed conflicts and displacement, natural disasters (floods, desert storm) or the Beirut (Lebanon) port explosion (August $4^{\text {th }}$ 2020). Also excluded were the reports presenting the operational response by governments and other supporting agencies, such as those describing ongoing collaboration between governmental and non-governmental partners as well as the implemented activities for supporting the delivery of basic healthcare, nutritional, and educational services.

Following, all retained publications and situation reports 
were reviewed and the extracted information was tabulated in a pre-designed ad-hoc synthesis table listing, per country and per publication, tackled COVID-19 pandemic measure(s) and their quantitative or qualitative effect measure on each component of the three exposome domains. Below, we are describing the impact of the COVID-19 pandemic measures on the exposomic profile of children in the EMR using the three exposome domains.

\section{PATIENT AND PUBLIC INVOLVEMENT IN RESEARCH}

Neither patients nor the public were involved in developing any aspect of this research (it is completely based on the secondary data), therefore no ethical approval was sought.

\section{RESULTS}

\section{DESCRIPTION OF THE SELECTED PUBLICATIONS}

The search yielded 91 hits on Pubmed and 314 on Google Scholar. The title screening of Pubmed and Google Scholar records identified 29 duplicates and 12 non-English publications, which were excluded. Out of the remaining 364 records, full-text screening excluded 348 publications (Figure 1). In total, 16 peer-reviewed research articles were retained: Saudi Arabia (n=6); Afghanistan (n=3); Egypt (n=3); Iran ( $n=2)$; Pakistan $(n=1)$; Qatar $(n=1)$. In parallel, 674 situation reports were additionally generated from Reliefweb of which 174 unique reports targeted EMR countries. Of these, 36 reports were retained: Syria $(n=13)$; Afghanistan $(n=5)$; 3 for each of Iraq, Somalia, Sudan and Yemen; 2 for each of Lebanon and the Occupied Palestinian Territories; and 1 for each of Libya and Pakistan (Figure 2). As per our selection criteria, no peer-reviewed research articles or situation reports were retained for other EMR countries, such as, Bahrain, Djibouti, Jordan, Kuwait, Morocco, Oman, Tunisia and United Arab Emirates.

\section{DESCRIPTION OF THE RETAINED PUBLICATIONS}

More than half $(n=10)$ of the 16 retained peer-reviewed studies were of cross-sectional design with variable sample size (range of 67-1507 participants). During the COVID-19 pandemic period, 3 studies described changes in the case management of children with a certain medical condition in Iran, ${ }^{19}$ Pakistan $^{20}$ and Saudi Arabia ${ }^{21} ; 3$ studies described the delayed vaccination patterns among children in Saudi Arabia, ${ }^{22-24}$ while 2 studies looked into children's behavioral changes in Qatar ${ }^{25}$ and Egypt, ${ }^{26}$ and 2 others tackled the impact of home confinement on children's relationship with their parents in Qatar ${ }^{27}$ and Saudi Arabia. ${ }^{28}$ Two papers analyzed the Poliomyelitis surveillance system performance indicators as well as national immunization activities taking place in Afghanistan and Pakistan. ${ }^{29,30}$ Retrospective review of medical records was used to study the impact of home confinement on missed vaccination opportunities for Saudi Arabian children (2-12 months old $)^{31}$ and on pediatric dental care among Egyptian children $(<15$ years old). ${ }^{32}$ One study conducted in Pakistan explored the emotional well-being and behavior changes among children aged 10-18 years, using a mixed design, targeting 189 school students with a cross-sectional survey and 9 children

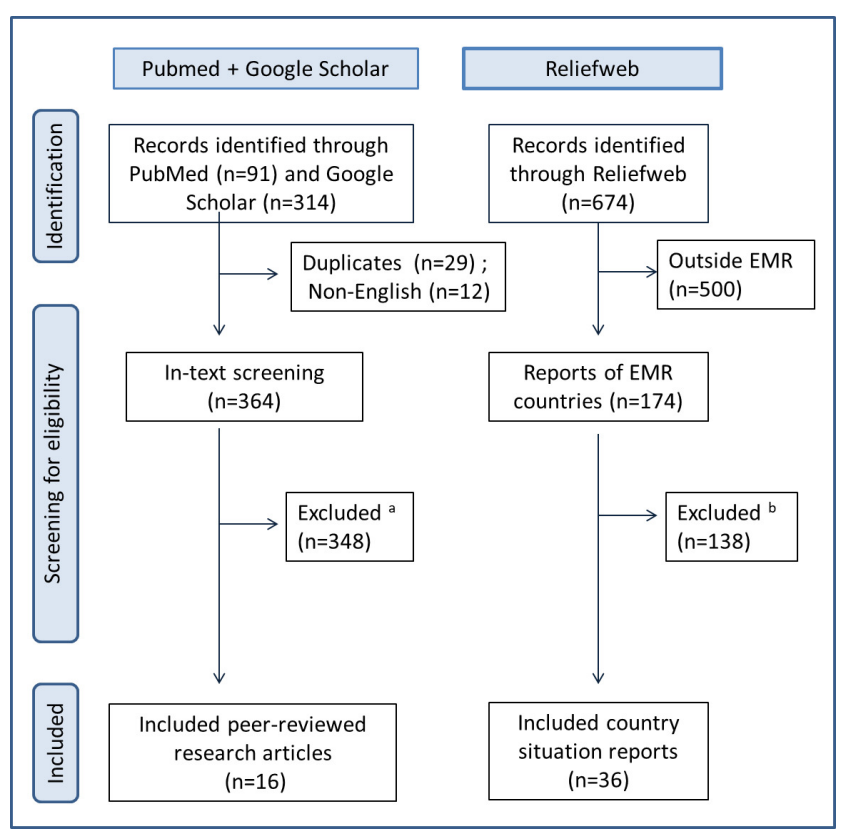

Figure 1. Flowchart of the selection process for the peer-reviewed articles and situation reports.

a Description of clinical and epidemiological characteristics of COVID-19 infection in the population, including children ( $\mathrm{n}=109)$; Editorials, commentaries, perspectives, policy briefs and other correspondence $(n=68)$; Provision of case management of COVID-19 in children ( $n=44$ ); Studies not targeting children $(n=42)$; Not conducted in the EMR $(n=40)$; Not COVID-19 related $(n=17)$; Describing or evaluating a practice or intervention (such as online learning, telemedicine, phone-based data collection) conducted during COVID-19 pandemic ( $n=16)$; Describing health or education systems or studies conducted before COVID-19 and the implemented NPI ( $n=5)$; Clinical trial protocols $(n=3)$; Assessing the acceptance rate of the COVID-19 vaccine uptake in the population $(n=1)$; Simulation of learning losses due to various lengths of school closure in Pakistan ( $n=1)$; Forecasting COVID-19 cases in Saudi Arabia ( $n=1)$; Knowledge, attitudes, and practices of Jordanian children toward COVID-19 ( $n=1)$;

${ }^{b}$ Situational and funding overview, partnerships and operational response $(n=123)$; Description of countries situation and response to other local crises in times of COVID-19 pandemic ( $\mathrm{n}=9$; 8 for Lebanon following Beirut Port explosion and 1 for Somalia Deyr season floods); Tackling families seeking refuge outside EMR $(n=4)$; Not related to children during COVID-19 pandemic $(n=2)$.

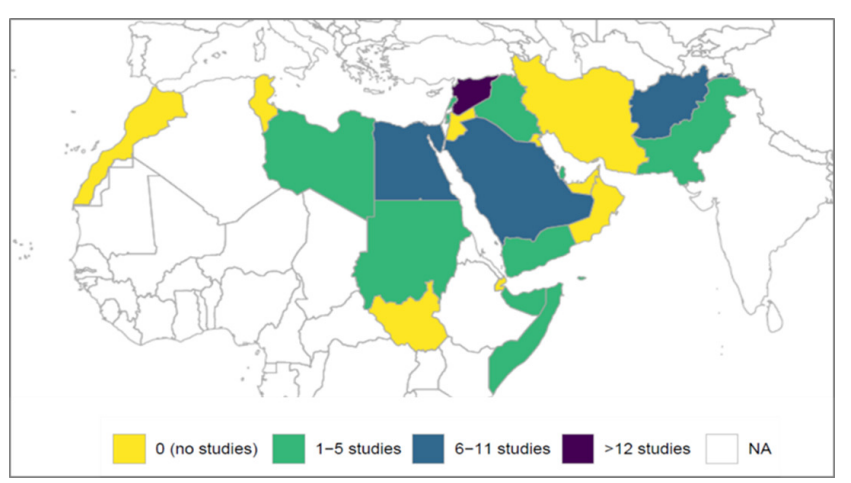

Figure 2. Map of the retained publications per EMR country.

with semi-structured interviews. ${ }^{33}$ A qualitative study among 17 mothers in Tehran (Iran) assessed the physical and mental concerns about their children (7-9 years) as a result of home confinement measures. ${ }^{34}$

Furthermore, multiple NPIs were simultaneously tackled 
in 36 retained situation reports. The quantitative and/or qualitative effects of COVID-19 NPI measures (e.g., stayat-home-orders, or home confinement) were evoked in $47 \%$ of the reports $(n=17)^{35-51}$; followed by those of the compound crisis of COVID-19 and other societal crises, such as ongoing political and economic instability in Lebanon, the Occupied Palestinian Territories, Somalia, Syria and Yemen. ${ }^{43,47,50-60}$ About $28 \%(n=10)$ of the reports tackled the effects of schools closure on the capacity to access distance learning and the risk of school dropout, $36,37,40,43,47,48,61-64$ while others $(n=4,11 \%)$ studied the effects on income losses due to home confinement and reduced economic activity. ${ }^{40,65-67}$

\section{THE IMPACT OF THE COVID-19 PANDEMIC AND ITS ASSOCIATED NON-PHARMACOLOGICAL INTERVENTIONS ON THE GENERAL EXTERNAL EXPOSOME DOMAIN OF CHILDREN}

The COVID-19 pandemic and its associated NPIs affected three key components of the general external exposome domain of children in the EMR: i) socio-economic constraints and children's exploitation associated with lost or reduced family income, ii) limited access to basic health, education and nutritional services, albeit overstretched in some of the EMR countries, prior to the COVID-19 period, and iii) mental health and child protection issues.

Lost or reduced family income has been during the COVID-19 crisis a major issue challenging children's wellbeing and further exacerbating children's health disparities. As of July 2020, it was estimated that $11.7 \%$ of the Iraqi population ( 4.5 million) were pushed below the poverty line as a result of the pandemic, while children's poverty ratio almost doubled from 1 to 2 out of 5 children, when compared to pre-pandemic estimates. ${ }^{66}$ The COVID-19 pandemic in conjunction with the political and economic instability in Lebanon supported an upward trajectory for unemployment and poverty rates, affecting both Lebanese and nonLebanese communities. Indeed, the COVID-19 crisis put an additional strain to the national inflation rate escalating from 31\% in March 2020 to $89 \%$ by June 2020, as well as to the permanent or temporary loss of income, affecting more than 220,000 individuals, since October 2019.57 As a result, it was estimated that approximately one-third of the Lebanese population would have fallen into extreme poverty during 2020. As for the Syrian refugees in Lebanon, $\sim 90 \%$ of Syrian refugee households $(n=4,563)$ across all the Lebanese districts lived below the extreme poverty line in August/September 2020, when compared to 55\% in mid-2019. ${ }^{47}$ Similarly for the Occupied Palestinian Territories, the socio-economic situation was worsened during the COVID-19 pandemic, impoverishing more families and compromising their capacity to sustain their children's education (risk of school drop-out). ${ }^{43}$ A family survey in Afghanistan ( $\mathrm{n}=409$ families) in June 2020 showed a noticeable loss of income for about half of them (47\%); about $90 \%$ of participating families reported a debt increase amidst lower humanitarian aid and negative coping mechanisms reportedly adopted by households to overcome shortage of income. ${ }^{40}$ Among families with reduced income, almost half of them reported engaging their children with the labour market, $11 \%$ reported sending them to street begging, $8 \%$ reported sending their children to relatives for food provision purposes, while $6 \%$ reported marrying off their minor daughters. ${ }^{40}$ Most participating families reported school drop-out and child labour as their most significant concerns for their children (69\% and 52\%, respectively), followed by early child forced marriages (16\%) and child abuse (13\%). ${ }^{41,68}$ An increasing number of children (10-16 years old) was involved in various forms of labour, such as shoe polishing, carrying loads, and collecting garbage, according to a multi-sectoral situation report issued in May-June 2020. ${ }^{39}$ A similar scenario was also showcased in a two-round survey (August and October 2020) among Syrian and other refugee households $(n=1605$, round 1 and $n=1653$ in round 2) sampled from all governorates of Iraq. Child labour and child marriages were increasingly reported by households as emerging trends to tackle economic downturn and generate family income (42\% and $17 \%$ of households in round 2 and $8 \%$ and $1 \%$ in round 1 , respectively). ${ }^{41,68}$ The trends of various forms of child exploitation were reportedly on the rise in Yemen and Syria with escalating child protection concerns. In Yemen, a field visit by UNHCR in July 2020 highlighted the increasing exposure of internally displaced children to labour, street begging and early marriage. ${ }^{69}$ In Northwest Syria, an increase in financially-driven negative coping mechanisms was also noted with an increasing number of families resorting to child labour, street begging and various forms of sexual abuse, such as forced prostitution, early and/or short-term marriages and abortions. ${ }^{58,65,69-71}$

Children's deprivation from basic services - already prevalent in some of the EMR countries in the preCOVID-19 era - was another major area of concern during the COVID-19 pandemic period. For instance, as early as March 2020 and right after the implementation of national lockdowns, the access of children to basic education and protection services in the West Bank of the Occupied Palestinian Territories and in Yemen was further compromised. ${ }^{36,45}$ In the EMR region where progress towards universal access to education is still stalled for various reasons, the pandemic driven closure of educational institutions further exacerbated the unequal access to distance/alternative learning opportunities, thus favoring the risk of school drop-outs among the most disadvantaged groups. ${ }^{72}$ In the Occupied Palestinian Territories, about half of the schoolaged population of the Gaza strip (575000 children and teenagers) were lacking access to information and technology infrastructure (such as power supply, computers and internet) as of December 2020. ${ }^{43}$ Similarly in Iraq, around $30 \%$ of the school-aged population or approximately 37 million were lacking access to education when school closure was ordered on February $27^{\text {th }} 2020 .{ }^{62}$ Later in June, despite efforts of providing alternative and distance learning solutions by the Iraqi government and operating agencies, it was estimated that around 10 million were still left out of school. ${ }^{64}$ Low percentage of at-home learning was also prevalent among families seeking refuge in Iraq between August and October 2020; only $41 \%$ of girls and $36 \%$ of boys continued home learning activities, despite engagement of schools and communities in e-learning from home. Barriers of distance learning were primarily identified as the inabil- 
ity of parents to support their children's learning process, as well as the lack of access to electronic resources, such as smart devices. ${ }^{41}$ Similar estimates were reported among Syrian refugee families in Lebanon with only $35 \%$ of schoolaged children between 6 and 17 years old having some sort of access to distance learning. ${ }^{47}$ Access to education was even lower in northwest Syria, where only $10 \%$ of 415,000 children were attending school via distance learning as of May $2020 .{ }^{63}$ In September 2020, around 82\% of key-informants reported through the Child Protection Area for Responsibility that children in northwest Syria were engaging into a form of child labour, which prevented them from continuing their education. ${ }^{50}$ In Afghanistan, where an estimated 3.7 million children were already out of school before the pandemic, more than 8 million children were deprived from several months of schooling during 2020. ${ }^{37,48,73}$ Less than half of participating families $(n=410)$ practiced distance learning for their children in a survey conducted in July 2020 in Herat, Ghor and Badghis, Afghanistan. ${ }^{74}$ School closures in Afghanistan was therefore perceived to exacerbate the risk of school drop-out, unpaid child labour and early marriages, particularly among the economically stressed families. ${ }^{73,75-77}$ An increased risk of school dropout was also reported for children in Libya; as schools were to resume towards the end of 2020, it was projected that many children would not have access to distance learning tools from home, risking school drop outs. ${ }^{61}$

Children's access to essential health services was also disrupted because of the lower availability of medical services, supply and logistics or due to movement restrictions imposed during the COVID-19 pandemic. As of June 2020 in Afghanistan, a significant reduction in the uptake of routine reproductive, maternal, newborn, child and adolescent health services was observed, because of the quarantine measures and movement restrictions, but also because of the de-prioritization of healthcare by fear of contracting COVID-19 virus. ${ }^{48}$ Similarly in Pakistan, access to HIV health services was adversely affected by the lockdown, thus, challenging treatment adherence to an ongoing outbreak among children under 14 years old, since April 2019.42 Also, children with intellectual disabilities were lacking access to physical and psychosocial therapy in Pakistan, as highlighted in a study among 67 parents, who at least $37 \%$ expressed difficulties with keeping in touch with their therapist. ${ }^{20}$ A decline in access of rehabilitation programs, physiotherapy and psychosocial counseling was observed among children with disabilities in Syria during the pandemic. ${ }^{50}$ In Egypt, emergency dental visits and the number of children ( $<15$ years old) seeking dental services was reduced by half in the 20 days following the implementation of the lockdown, as compared to the 20 days period, prior to the lockdown. ${ }^{32}$

Vaccination services were also interrupted leaving millions of children across the EMR with missed immunizations. In Pakistan, the cancellation of nationwide vaccination campaigns since April 2020 left around 40 million children without their Poliomyelitis vaccination. ${ }^{29}$ In Sudan, around 110,000 children missed out their essential vaccination services because of closed health clinics. ${ }^{45}$ The choice of delaying vaccination of children was a parental decision by fear of contracting the virus in Saudi Arabia; a national study conducted in May 2020 among a convenient sample of 822 parents of children ( $<4$ years old) revealed that $47 \%$ of them expressed difficulties completing their child's vaccination during the pandemic, while $24 \%$ missed their vaccination schedule during the pandemic, ${ }^{22}$ while a third of children $(<6$ years old) missed out on their vaccination during COVID-19, particularly because of fears visiting healthcare facilities between July and September 2020 ( $n=494$ parents). ${ }^{23}$ Similarly, a study conducted in June 2020 among 749 parents conveniently sampled in the Qassim region of Saudi Arabia, showed that vaccination for children $(<2$ years old) was delayed by $>2$ weeks for about half of the respondents and more than a month for $23 \%$ of respondents, while fear of contracting the SARS CoV-2 virus was the most common reported reason for delayed vaccination (61\%). ${ }^{24}$ This trend of missed vaccinations was also documented in a retrospective review of hospital-based vaccination records of 15,870 children (2-12 months) in Saudi Arabia, comparing the number of vaccination visits between the 2017 and 2020 periods; the number of vaccinations during 2020 was the lowest among the past 4 years (by almost one fourth) with only 1,735 visits in 2020 when compared with 4,501 in 2019; 4,593 in 2018 and 5,041 in 2017.31

The psychological impact on the EMR children associated with the socio-economic distress, disruption of essential services, and movement restrictions was quite noticeable in the region during the COVID-19 pandemic. Worrisome concerns of rising child exploitation and protection issues with increasing observations of gender-based and domestic violence, physical and emotional abuse and harassment were noted in several country situation reports of Afghanistan, ${ }^{38,40}$ northwest Syria ${ }^{59,66,75}$ and Yemen. ${ }^{69}$ Access to child protection services was challenged due to COVID-19 restrictions, as noted in Sudan in June 2020, where the identification of children under stress at school and child-friendly spaces was impeded by school closures and movement restrictions. ${ }^{49}$ In Lebanon, the number of child protection case management requests decreased by 39\% in September 2020 when compared to mid-2019 requests, namely because of the COVID-19 mobility restrictions, adversely impacting on the timely identification of referral cases. Nevertheless, case requests for management of child violence (e.g., psychological abuse) almost doubled in June 2020, when compared with pre COVID-19 period. 57 Based on 2020 estimates for Sudan, access to prevention and child protection services for 45,408 cases of care seeking among female survivors of sexual violence aged 15-49 years old was severely challenged by the COVID-19 mobility constraints. 46

Laziness and boredom were the most commonly reported feelings by children between 10 and 18 years old during the COVID-19 pandemic period as reported in a qualitative study $(n=9)$ and a quantitative study $(n=189)$ in Pakistan during May 2020.33 A survey in Egypt during May 2020 ( $n=1507$ school children, 6-14 years of age) showed that sleep patterns for almost $96 \%$ of quarantined children were somewhat affected (either in terms of duration, time, quality, difficulty falling asleep, or returning to bedwetting). ${ }^{25}$ Worries about the COVID-19 pandemic took the form of constant inquiry about symptoms and their severity for most of children (90\%), while $26 \%$ of them reported fre- 
quent checking for symptoms, looking at the mirror to assess if they look healthy (23\%) or asking their parents to take their body temperature (8\%). ${ }^{25}$ Children's worries were also expressed via their inability to carry out their usual daily activities (47\%) and their excessive use of handwashing and disinfectants (43\%), while $46 \%$ of them reported no longer being able to carry out their usual daily activities. ${ }^{25}$ Aggressive behavior was the most reported mood and behavior change (58\%), while loss of concentration was a major parental concern as children were reportedly not being able to complete their assignment or to answer simple questions (38\% and $24 \%$, respectively). ${ }^{25}$ Nevertheless, other studies pointed out the reduced conflict score and increased closeness score, modified from a Child Parent Relationship scale among children and their parents during home confinement, particularly because of longer hours spent at home together; a convenience sample of parents $(n=377)$ in Saudi Arabia between April and June 2020 showed reduced tension during lockdown as compared to pre-lockdown period. ${ }^{28}$ The positive association between parental engagement in activities and enhanced mental health for children during home confinement was highlighted in a national study among parents $(n=308)$ that took place in Qatar between June and July 2020. ${ }^{27}$

\section{THE IMPACT OF COVID-19 AND ITS ASSOCIATED NON- PHARMACOLOGICAL INTERVENTIONS ON THE SPECIFIC EXTERNAL EXPOSOME DOMAIN OF CHILDREN}

With the suspension of immunization activities and the imposed mobility/contacts restrictions due to the pandemic, the resurging risk of pediatric vaccine-preventable diseases is not to be neglected in the EMR region. This could be further exacerbated by the parental choice of delaying their children's vaccination until the end of the pandemic. Measles outbreaks continued to be reported across Somalia with hundreds of cases as of September $2020 .{ }^{78,79}$ The isolation of vaccine-derived poliovirus (VDPVs) from both environmental and human samples in Somalia and Sudan between July and September 2020 were highly suggestive of poor vaccination coverage, hence, warranting for urgent vaccination campaigns to protect millions of children in the affected areas. ${ }^{80-84}$ In Afghanistan, where poliomyelitis was reportedly eliminated in $96 \%$ of the country's jurisdiction, a total of 41 confirmed cases of Wild Poliovirus Type 1 (WPV1) appeared as of August 2020, when compared to 29 and 21 cases in 2019 and 2018, respectively. 30

Communities in the EMR with persistent challenges in accessing safe water, sanitation and hygiene may be particularly vulnerable due to the COVID-19 crisis. In Afghanistan, the increased time spent by girls and women in fetching water as compared to pre-COVID-19 levels put them at higher risk of contracting the virus. ${ }^{38}$ As of November 2020 in Sudan, lack of access to basic sanitation was affecting $~ 63 \%$ of the population; about $40 \%$ of the population was lacking access to drinking water services and $23 \%$ had no access to hand-washing facilities. In Sudan, cases of water-borne and diarrheal diseases have been on an upward trajectory doubling in October 2020, up from 5.6 million cases in April 2020 during the implementation of COVID-19 response measures and the natural disaster (floods) that se- verely affected the country. ${ }^{45}$

Dietary habits of children were also affected by the pandemic risk management and its NPIs. A crisis of emergency food insecurity was flagged in several EMR countries, because of reduced family income and increased food basket prices. In Syria, the price of an average food basket in November 2020 increased by $250 \%$ when compared to the previous 12 months, placing more than 4.5 million children in need of humanitarian assistance. ${ }^{50}$ In Afghanistan, the levels of food insecurity by the end of 2020 were similar to those observed during the 2018 drought; between November 2020 and March 2021, an estimated 16.9 million were facing a crisis of food insecurity ${ }^{73}$; the survey ( $n=409$ families) conducted in June 2020 highlighted the coping measures by the families who reported decreases in daily meal consumption rate (32\%), while the proportion of children having 3 meals per day decreased by $4 \%$ (from $64 \%$ to $60 \%$ ) when compared to pre-pandemic levels. ${ }^{40}$

On the other hand, the adoption of a sedentary lifestyle driven partially by stay-at-home-orders during the COVID-19 crisis favored the choice of unhealthy dietary habits, as showcased in a convenience sample among 765 parents across Egypt (May 2020, after two months of lockdown $)^{26}$; changes in dietary patterns of their children (4-16 years old) were on the rise as noted for late night snacking (53\%), sweets and unhealthy food consumption (46\%), frequent snacking between meals (38\%) and increased appetite (31\%). ${ }^{85}$ Increased mood-driven eating was similarly observed among the 1507 surveyed school children in Egypt (78\%), along with changes in sleeping patterns (avoiding bedtime, difficulty falling asleep) (96\%). ${ }^{25}$

\section{THE IMPACT OF COVID-19 AND ITS ASSOCIATED NON-} PHARMACOLOGICAL INTERVENTIONS ON THE INTERNAL EXPOSOME OF CHILDREN

The historically prevalent phenomenon of severe acute malnutrition (SAM) in the EMR region during the past few years was further exacerbated during the COVID-19 pandemic, because of food insecurity challenges. As such, there was an increased risk of wasting and stunting (impaired growth and development) among children in several EMR countries, such as Pakistan ${ }^{42}$ and Somalia. ${ }^{55}$ Intervention efforts to tackle the high prevalence of wasting among young children in Pakistan, affecting 1 in 6 children as per estimates of 2018 were challenged in 2020 by the COVID-19 pandemic, posing an alarming threat to under-five children's mortality rates. ${ }^{42}$ Between January and November 2020 in Somalia, the total SAM admissions exceeded the 2020 annual target of the United Nations International Children's Emergency Fund (UNICEF) by 60\%, and the overall country burden by $20 \% .{ }^{55}$ In Syria, SAM cases increased by $70 \%$ between March and December 2020, as compared to the same period in 2019.50 Approximately one third of children $<5$-years old experienced stunting, representing a 5\% increase between January and October 2020.56 In Yemen, "the window for preventing famine was closing" as warned by the United Nations in December 2020, with pockets of famine-like-conditions returning to the country after two years; The number of families experiencing high levels of food insecurity was estimated to triple during the first six 
months of 2021, escalating from 16,500 in 2020 to 47,000 between January and June 2021.53 After 80 days following the lockdown in Iran, weight gain was reported by 17 mothers for their children (7-9 years) due to a sedentary lifestyle and changes in dietary patterns. ${ }^{34}$

Children with a pre-existing medical condition were also affected by the mobility restrictions, home confinement, and modifications in case management during the pandemic. According to a study conducted during April-June 2020 on a sample of type 1 diabetic children $(n=150,2-18$ years old), the proportion of those taking 4 daily doses of insulin increased from $25 \%$ before the lockdown to $33 \%$ during the lockdown as the proportion of those following an unhealthy diet had doubled during the same period. ${ }^{21}$

\section{DISCUSSION}

This comprehensive analysis puts forward important issues of children's health in the EMR through the calamity of COVID-19 and its implemented NPI measures. Various child support programs have been impeded during the pandemic in several EMR countries that historically face enormous children's health challenges, thus hindering the progress in the field. The human exposome concept provided us with a comprehensive characterization of the children's exposome profile in the EMR as impacted by the suite of implemented NPI measures during the pandemic. This work highlighted the wider impact the COVID-19 pandemic on children's health and wellbeing that appears to be disproportionately affecting children of lower- and middle-income countries, such as those in the EMR region.

The analysis of the literature for the children in the EMR region made quite obvious that the suite of pre-pandemic basic health and educational services of childhood was disrupted or made less available during the pandemic period, all compounded by stark socio-economic, psychological, and access to nutrition disparities (all part of the general external exposome domain). This unfortunate series of obstacles on the availability and reliable implementation of health policy programs and services during the pandemic for the EMR childhood was accompanied by a series of changes in the children's specific external exposome domain (e.g., unhealthy dietary patterns, sedentary lifestyle and increased risk to communicable diseases). Molecular epidemiology and biomarker studies to reflect the endogenous response due to external stimuli (internal exposome domain) were not available for the EMR region; rather, the most frequently studied component of the internal exposome domain of the EMR children during the pandemic was the impaired growth due to sub-optimal nutrition. ${ }^{86}$

Although operational responses continue to be implemented during the pandemic period, albeit less in frequency and reach-out, supporting access to education for all children in the EMR remains most challenging, particularly for children living in countries affected by political instability and armed conflict, children of refugees and internally displaced populations. The dual shock of the COVID-19 pandemic and the reductions in oil price cost ( 116 billion U.S. Dollars, or 3.7\% of the region's GDP) for the MENA region ${ }^{87}$ did not help to sustain efforts towards bridging gaps and disparities fueled by socio-economic dis-

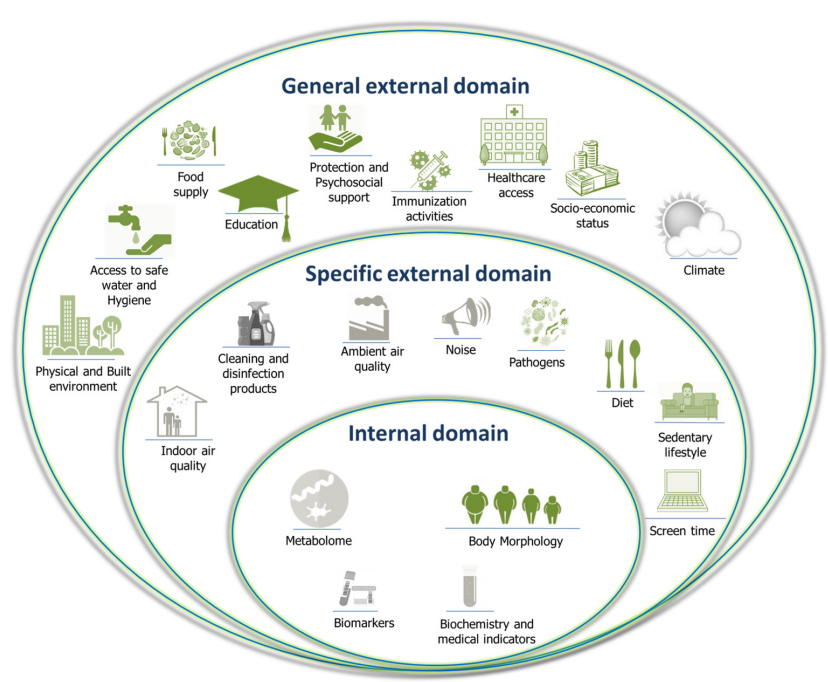

Figure 3. A schematic illustration of the children's exposome components impacted by the COVID-19 response measures in the EMR as documented by the retained publications (in dark green) and those exposome components not discussed in the retained publications (in grey).

parities. Fragile incomes of mainly low-income families, refugees and displaced groups, were the "first ones to disappear in situations of lockdowns", thus further increasing their vulnerability to pandemic stressors. ${ }^{88}$ Millions of children worldwide, mostly belonging to low-income families and refugees could be pushed into the labour market during the COVID-19 period, hence leading the first rise in children's trauma and violence metrics after 20 years of progress in the field, as stated by the International Labour Organization and UNICEF. ${ }^{72}$ In the MENA region, where 1 in 10 children were engaged in some form of child labour between 2009 and 2015, this ratio is expected to grow during the COVID-19 period, thus, increasing children's vulnerability to a suite of environmental stressors. ${ }^{89-91}$ More alarmingly, as psychological distress and negative coping mechanisms increase, children are at a higher risk of domestic and gender-based violence, increased street work and begging, engagement in illegal activities as well as increased risk of arrest and detention. ${ }^{92}$ Hence, their exposure to physical, biological, and chemical hazards as well as psychological distress causing injuries and illnesses are expected to increase in the near future.

Child marriage (before they reach their $18^{\text {th }}$ birthday) is another social issue already prevalent in the region. Years of planned efforts to end child marriages are at risk due to COVID-19 related projections for an additional 13 million child marriages between 2020 and 2030, worldwide (mostly in the MENA region) that could have otherwise been prevented. ${ }^{93,94}$ Mental health impacts due to the economic and social distress, such as post-traumatic stress were indeed noted across several countries since the first COVID-19 stay-at-home-orders. ${ }^{93}$ With the disruption of curricular activities along with their ambiguously planned resuming dates in some of the countries on one hand, and fears of losing a relative to COVID-19, children might be prone to ex- 
periencing feelings of anxiety and insecurity about their future, as well as lack of attention/concentration and reduced ability to perform usual daily activities. Further, home confinement was associated with prolonged unsupervised screen time, subjecting children to inappropriate online content, sexual exploitation and cyber bullying, which might lead eventually to intentional self-harm and suicidal ideation. ${ }^{94}$ Nevertheless, a potentially beneficial effect of NPIs was noted, as some studies showed positive association between parental engagement in activities and enhanced mental health for children. ${ }^{27,28}$

Missed or delayed vaccinations in the region with suboptimal vaccination coverage during the COVID-19 period have put millions of children at higher risk of pediatric vaccine-preventable diseases. In case immunization activities are suspended for quite longer than the lockdown periods, millions of children in the region will be left with a lack or incomplete vaccination against essential vaccinepreventable diseases, hence holding back decades of efforts made by governments and health organizations in reducing related-morbidity and mortality as well as achieving elimination or eradication goals. ${ }^{95,96}$ As five out of six WHO regions were certified polio-free in August 2020, the COVID-19 crisis is hence posing major threats in hindering the eradication efforts that have been achieved during the past decade in the EMR. ${ }^{30}$

\section{UNDERSTUDIED EXPOSOME COMPONENTS OF CHILDREN'S HEALTH IN THE EMR}

Looking through the lens of the human exposome, numerous components of the specific external and the internal exposome domains were not tackled in any of the retained reports and publications for the EMR childhood population. Although temporary reductions in the concentrations of ambient gaseous and particulate air pollutants globally and regionally were noted during the COVID-19 lockdown periods around the globe, these air pollution metrics were not tackled in any of the selected studies. ${ }^{97-100}$ The link between ambient indoor and outdoor air pollution and adverse health outcomes is well established in the region; Nevertheless, research on the negative health impact of air pollution is already scarce in the region, as this is not quite yet perceived as a public health priority, struggling with other existing pressing public health challenges, such as the prevalence of communicable diseases. ${ }^{101,102}$

Mobility restrictions further increased children's time spent indoors, being more prone to indoor air pollution. Some studies in the EMR showed positive associations between children's (between 6 months and 15 years old) exposures to indoor stressors, such as Arabian incense burning, ${ }^{103,104}$ second hand smoking, 105,106 indoor pollutants and allergens, ${ }^{107-112}$ and house dust mite ${ }^{110}$ and a suite of respiratory and neurologic health outcomes (such as asthma, respiratory complaints and lung function) in countries of the EMR region (Oman, Egypt, Qatar, Iran, Kuwait, Saudi Arabia, Sudan, Lebanon and Libya). Other forms of indoor pollution arising from poor housing and infrastructure conditions (such as mold, damp walls and floors, leaking pipes) were linked to adverse acute and chronic health effects among children. ${ }^{111}$ Disinfection-by-products were associated with a wide intentional/unintentional use of alcohol-based hand sanitizers and disinfectants during the COVID-19 pandemic as documented for children during the COVID-19 confinement periods. A growing number of chemical poisoning incidents from the inhalation of cleaning and disinfection products among children were reported in other parts of the world during the pandemic period when compared with those of previous years. ${ }^{113,114}$ Nevertheless, up to date, no studies have tackled the effects of such exposures in the EMR region during the COVID-19 crisis.

As access to recreational parks and outdoor playgrounds is restricted while stay at home orders prevail, children would likely favor sedentary activities, such as watching television, playing video games, and increased screen time. Children's sleeping patterns might also be altered with extended bedtime and allowed prolonged recess during the day. Dietary habits would be also affected, as confined children would likely increase the consumption of ultra - processed, calorie - dense comfort foods and ready-toeat meals by children between 3 and 16 years old in Dubai, United Arab Emirates. 85

These lifestyle and behavioral exposures of the general and specific external exposome domains of the children would have been imprinted onto their endogenous response. Perhaps the most tangible outcome would be a change in children's body weight. With the disrupted nutritional services and the exacerbated food crisis, the impaired growth development among children was the main issue of concern as millions of families are approaching the faminelike conditions, particularly in Yemen. ${ }^{53}$ However, none of the retained publications tackled the decreased physical activity and increased unhealthy eating, making children more prone to gain weight and facilitating the gradual accumulation of abdominal fat. The prevalence of overweight preschool children (< five years old) ranged between $2 \%$ in Oman and 20\% in Syria; concerns over increasing prevalence of diseases associated with childhood obesity (e.g., metabolic syndrome, hypercholesterolemia, fatty liver disease, type II diabetes, asthma, sleep apnea) were also raised over the past years in several studies conducted in the region. ${ }^{113,115}$ On the other hand, stunting of growth prevailed among malnourished children in the region; estimates ranging from $8 \%$ in Qatar to $53 \%$ in Yemen were more likely to be exacerbated among children undergoing severe malnutrition in countries facing food crisis. ${ }^{114}$

The effects of COVID-19 response measures on the human endogenous response taking the form of a suite of targeted molecular biomarkers have not been effectively tackled for the EMR. Nevertheless, studies have been conducted to assess the changes in inflammatory, hematologic, and biochemical biomarkers in association with COVID-19 infection and disease severity among children and adults. ${ }^{116-120}$ One study conducted among different age groups in Italy did not document any changes in $1 \alpha, 25-(\mathrm{OH}) 2 \mathrm{D}$ in association with home confinement. ${ }^{119}$ Although not studied among children yet, the impact of changes in diet and lifestyle resulting from COVID-19 lockdown on serum biomarkers in children such as the reduction in vitamin D is speculated. ${ }^{120}$ Hence, evaluating the variability in the internal exposome of children as a result 
of external COVID-19 pandemic measures would offer valuable insight on possible long-term adverse health outcomes.

The strength of our narrative review lies in the holistic approach embodied by the exposome framework, allowing for the comprehensive and simultaneous assessment of the impact of COVID-19 response measures on the network of population-level and individual-level environmental exposures for the children of the EMR. In contrast to the conventional epidemiological tools using the single exposure-outcome approach, the exposome concept - in the particular context of the COVID-19 crisis - showcased the methodological framework and its tools in assessing how the intertwined COVID-19 response measures and their cross-cutting repercussions would affect the overall well-being and quality of life for the EMR children. Our review could serve as an example on the utility of the exposome framework in designing and facilitating the implementation of COVID-19 action and recovery programs. Nevertheless, standardizing the recovery actions and programs for the whole EMR region might be further challenged by the existing inequalities and vulnerabilities between and within the EMR countries. Additionally, for the development of sustainable recovery programs, it is important to assess the mediumand longer-term impact of COVID-19 response measures on children's health. Equally important, is that by pooling results from reports generated for different EMR countries, there is a risk for high heterogeneity in the observed trends, impacting the generalization of the findings.

The EMR is an understudied region with respect to its children's health, let alone during a global crisis like the COVID-19 pandemic. Thus, this review brings forward updated research and knowledge gaps about children's health profile that authorities and international entities could start filling in the near future.

\section{CONCLUSIONS}

To the best of our knowledge, this work is the first to comprehensively examine the overall impact of COVID-19 measures on children's health and quality of life metrics in the EMR region, using the exposome concept. ${ }^{122}$ It was highlighted that the magnitude and severity of the COVID-19-related NPIs impact on the region's children health and well-being was compounded by the EMR region's lower- and middle-income status. Efforts by national and international programs to tackle historical EMR challenges of child protection, promotion of education for all children, and eradication of malnutrition and pediatric infectious diseases seem to be at risk during the COVID-19 crisis, either due to inaction or suspension of children's services and programs in the EMR. It is of utmost importance to include the above-mentioned challenges into strategic COVID-19 recovery programs, such as the CAP2030 initiative, ${ }^{10}$ or in programs that reflect international human rights, such as the 1989 treaty on the United Nations Convention on the Rights of the Child.

Thus, a comprehensive reform and recovery plan tackling root causes of the pandemic response measures (e.g., lockdown, and other NPIs), which have stalled progress on children's health, is warranted. The exposome lens would be most useful in comprehensively considering all relevant children's exposome components that drive children's health status and trajectories. Such plan can be efficiently deployed only when sought in conjunction with the 17 Sustainable Development Goals (SDGs). ${ }^{123}$ Amidst a current resurge in the number of COVID-19 cases in the EMR region and elsewhere, regional authorities and governmental bodies are urgently pledged to consider the impact of the suite of COVID-19 response measures on every single exposome component of each of the exposome domains towards the deployment of multi-sectoral comprehensive action and recovery plans to the benefit of the children in the EMR region.

\section{ACKNOWLEDGEMENTS}

KCM would like to thank the EXPOSOGAS project that received funding from the European Union's Horizon 2020 research and innovation programme under grant agreement No 810995.

\section{ETHICS}

The protocol of this review does not require ethical approval because the research will be based on publicly available data.

\section{DATA SHARING STATEMENT}

No additional data available

\section{FUNDING}

The EXPOSOGAS project has received funding from the European Union's Horizon 2020 research and innovation programme under grant agreement \#810995.

\section{AUTHORSHIP CONTRIBUTIONS}

$\mathrm{NH}$ and KCM conceived the study. NH conducted the literature search and NH with HAN synthesized the information of retained publications. $\mathrm{NH}$ drafted the initial manuscript. KCM and HAN revised it critically for important intellectual content. All authors approved the version for submission.

\section{DISCLOSURE STATEMENT}

The authors completed the Unified Competing Interest form at www.icmje.org/coi_disclosure.pdf (available upon request from the corresponding author) and declare no conflicts of interest.

\section{CORRESPONDENCE TO:}

Dr Konstantinos C. Makris. Associate Professor of Environmental Health, Cyprus International Institute for Environmental and Public Health, Cyprus University of Technology. Irinis 95, Limassol 3041, Cyprus.

konstantinos.makris@cut.ac.cy 
Table 1. Summary of the impact of non-pharmacological interventions deployed during the COVID-19 pandemic on children's health in the Eastern Mediterranean region, by exposome component.

\begin{tabular}{|c|c|c|c|}
\hline $\begin{array}{l}\text { Non- } \\
\text { Pharmacological } \\
\text { Intervention }\end{array}$ & Exposome & Outcome & Country \\
\hline \multirow{9}{*}{$\begin{array}{l}\text { Collective } \\
\text { COVID-19 } \\
\text { related } \\
\text { restrictions } \\
\text { (mobility; stay- } \\
\text { at-home orders) }\end{array}$} & \multirow{2}{*}{ Food supply } & $\begin{array}{l}\text { Increasing acute and chronic malnutrition in children } \\
\text { 6-59 months; Aggravated nutritional status for children } \\
\text { under 5; Increased risk of under } 5 \text { mortality }\end{array}$ & $\begin{array}{l}\text { Syria } \\
\quad \text { Pakistan }^{42}, 51,54,56,59,60\end{array}$ \\
\hline & & $\begin{array}{l}\text { Projected increase in emergency food insecurity; } \\
\text { Reduced quantity of available meals for children }\end{array}$ & $\begin{array}{l}\text { Afghanistan }{ }^{36,38,40} \\
\text { Lebanon }^{47} ; \text { Yemen }^{53} \\
\text { Somalia } \\
\text { Som }\end{array}$ \\
\hline & \multirow{2}{*}{$\begin{array}{l}\text { Protection } \\
\text { and } \\
\text { Psychosocial } \\
\text { support }\end{array}$} & $\begin{array}{l}\text { Increasing negative coping mechanisms and gender- } \\
\text { based violence; Decreasing identification of children } \\
\text { needing psychosocial assistance; }\end{array}$ & $\begin{array}{l}\text { Afghanistan } 37,39,40,75-77 \\
\quad \text { Sudan }^{46,49}\end{array}$ \\
\hline & & $\begin{array}{l}\text { Increasing child labor, forced prostitution, forced } \\
\text { abortions and early/forced marriages }\end{array}$ & Syria 65,67 \\
\hline & $\begin{array}{l}\text { Socio- } \\
\text { economic } \\
\text { status }\end{array}$ & $\begin{array}{l}\text { Increasing poverty rates; Reduced financial capabilities; } \\
\text { Increasing negative coping mechanisms; Increasing } \\
\text { number of children in need of assistance }\end{array}$ & $\begin{array}{l}\text { Afghanistan } 40 \\
\text { Iraq } \\
\text { 41,66; Lebanon } 47,57 \\
\text { Occupied Palestinian } \\
\text { Territories } \\
\text { Syria; } \\
\text { Y0,58,70,71,121; } \\
\text { Yemen } 52\end{array}$ \\
\hline & \multirow{4}{*}{$\begin{array}{l}\text { Healthcare } \\
\text { access }\end{array}$} & $\begin{array}{l}\text { Reduction in uptake of healthcare services; Reduction in } \\
\text { child health and nutrition services; Decline in access to } \\
\text { rehabilitation programs, physiotherapy and } \\
\text { psychosocial counselling }\end{array}$ & $\begin{array}{l}\text { Afghanistan } 48 \text {; Occupied } \\
\text { Palestinian Territories }{ }^{44} \text {; } \\
\quad \text { Syria }{ }^{50} \text { Yemen }^{35}\end{array}$ \\
\hline & & Incomplete adherence to anti-retroviral HIV treatment & Pakistan 42 \\
\hline & & Lack of access to water and hygiene facilities & $\begin{array}{l}\text { Afghanistan } 38,73 \\
\text { Sudan } \\
\end{array}$ \\
\hline & & $\begin{array}{l}\text { Missed vaccination opportunities; Increase in the } \\
\text { number and geographical spread of poliomyelitis; } \\
\text { Continuous spread of Measles and vaccine-derived } \\
\text { Poliomyelitis; Threat of water-borne and diarrheal } \\
\text { diseases }\end{array}$ & $\begin{array}{l}\text { Afghanistan }{ }^{30} \\
\text { Pakistan } \\
\text { Sud } \\
\text { Sudan } \\
{ }^{45}\end{array}$ \\
\hline \multirow[t]{2}{*}{ Schools closure } & Education & $\begin{array}{c}\text { Challenged access to distance learning; Increasing risk } \\
\text { of drop-out }\end{array}$ & $\begin{array}{l}\text { Afghanistan }{ }^{37,40,48} ; \\
\text { Iraq } 41,62,64 ; \text { Lebanon }^{47} \\
\text { Libya }^{61} \text {; Occupied } \\
\text { Palestinian Territories } \\
\text { Syria } \\
\text { Sy }\end{array}$ \\
\hline & $\begin{array}{l}\text { Immunization } \\
\text { activities }\end{array}$ & Delayed or missed vaccinations & $\begin{array}{l}\text { Saudi Arabia24; } \\
\quad \text { Pakistan }\end{array}$ \\
\hline \multirow{4}{*}{$\begin{array}{c}\text { Home } \\
\text { confinement }\end{array}$} & $\begin{array}{l}\text { Protection } \\
\text { and } \\
\text { Psychosocial } \\
\text { support }\end{array}$ & $\begin{array}{l}\text { Changes in sleeping; Psychological changes (Increased } \\
\text { anxiety, irritability and aggressiveness; feelings of fear } \\
\text { and loneliness); Increased self-perceived health and } \\
\text { physical concerns; Conflict with parents }\end{array}$ & $\begin{array}{l}\text { Egypt } 25,26 ; \operatorname{Iran}^{19,34} \\
\text { Qatar } \\
\text { Saudi Arabia } \\
\text { Pakistan } \\
\text { P3 }\end{array}$ \\
\hline & Diet & $\begin{array}{c}\text { Changes in eating patterns (eating in late hours of the } \\
\text { night, overeating or losing appetite; changes in } \\
\text { consumed food) }\end{array}$ & Egypt 25 \\
\hline & \multirow{2}{*}{$\begin{array}{l}\text { Healthcare } \\
\text { access }\end{array}$} & $\begin{array}{l}\text { Decreased uptake of pediatric dental services; Effect on } \\
\text { case management of children with underlying condition }\end{array}$ & $\begin{array}{l}\text { Egypt }^{32} ; \text { Saudi Arabia } \\
\text { Pakistan } \\
\text { Pa }\end{array}$ \\
\hline & & Delayed vaccination by fear of contracting Sars-CoV-2 & $\begin{array}{l}\text { Saudi Arabia22,23,31; } \\
\text { Syria }\end{array}$ \\
\hline
\end{tabular}

Submitted: June 05, 2021 GMT, Accepted: June 16, 2021 GMT

This is an open-access article distributed under the terms of the Creative Commons Attribution 4.0 International License (CCBY-4.0). View this license's legal deed at http://creativecommons.org/licenses/by/4.0 and legal code at http://creativecommons.org/licenses/by/4.0/legalcode for more information. 


\section{REFERENCES}

1. Andrianou XD, Pronk A, Galea KS, et al. Exposomebased public health interventions for infectious diseases in urban settings. Environ Int.

$2021 ; 146(106246)$. doi:10.1016/i.envint.2020.106246

2. Wild CP. Complementing the Genome with an "Exposome": The Outstanding Challenge of Environmental Exposure Measurement in Molecular Epidemiology. Cancer Epidemiol Biomarkers Prev. 2005;14(8):1847-1850. doi:10.1158/1055-9965.epi-0 5-0456

3. Wild CP. The exposome: from concept to utility. Int J Epidemiol. 2012;41(1):24-32. doi:10.1093/ije/dyr236

4. de Souza TH, Nadal JA, Nogueira RJN, Pereira RM, Brandão MB. Clinical manifestations of children with COVID-19: A systematic review. Pediatr Pulmonol. 2020;55(8):1892-1899. doi:10.1002/ppul.24885

5. Ludvigsson JF. Systematic review of COVID-19 in children shows milder cases and a better prognosis than adults. Acta Paediatr. 2020;109(6):1088-1095. do i:10.1111/apa. 15270

6. Bhopal SS, Bagaria J, Olabi B, Bhopal R. Children and young people remain at low risk of COVID-19 mortality. The Lancet Child \& Adolescent Health. 2021;5(5):e12-e13. doi:10.1016/s2352-4642(21)0006 $\underline{6-3}$

7. Nicola M, Alsafi Z, Sohrabi C, et al. The socioeconomic implications of the coronavirus pandemic (COVID-19): A review. Int J Surg. 2020;78:185-193. do i:10.1016/i.ijsu.2020.04.018

8. Zar HJ, Dawa J, Fischer GB, Castro-Rodriguez JA. Challenges of COVID-19 in children in low- and middle-income countries. Paediatr Respir Rev. 2020;35:70-74. doi:10.1016/j.prrv.2020.06.016

9. Organisation for Economic Co-operation and Development. Combatting COVID-19's effect on children. Accessed August 9, 2020. https://www.oec d.org/coronavirus/policy-responses/combatting-covi d-19-s-effect-on-children-2e1f3b2f/

10. Dalglish SL, Costello A, Clark H, Coll-Seck A. Children in All Policies 2030: a new initiative to implement the recommendations of the WHO-UNICEF-Lancet Commission. The Lancet. 2021;397(10285):1605-1607. doi:10.1016/s0140-673 6(21)00718-2
11. United Nations Children's Fund. Between a rock and a hard place: COVID-19 doubles the burden for millions of children in the Middle East and North Africa Region. Accessed August 9, 2020. https://ww w.unicef.org/mena/press-releases/between-rock-andhard-place-covid-19-doubles-burden-millions-childr en-middle-east

12. World Health Countries. Eastern Mediterranean Regional Office, Countries. Accessed September 12, 2020. http://www.emro.who.int/countries.html

13. United Nations Children's Fund. COVID-19 pandemic could devastate refugee, migrant and internally displaced populations without urgent international action. Accessed August 9, 2020. http s://www.unicef.org/iraq/press-releases/covid-19-pand emic-could-devastate-refugee-migrant-and-internall y-displaced

14. United Nations. Global Humanitarian Response Plan COVID-19. Accessed January 21, 2021. https://w ww.unocha.org/sites/unocha/files/GHRP-COVID19 Ju ly_update.pdf

15. Our World in Data. Policy Responses to the Coronavirus Pandemic, Statistics and Research. Accessed September 30, 2020. https://ourworldindat a.org/policy-responses-covid

16. Covid Tracker. Accessed March 6, 2021. https://cov idtracker.bsg.ox.ac.uk/stringency-scatter

17. United Nations Children's Fund. The Convention on the Rights of the Child: The children's version. Accessed November 27, 2020. https://www.unicef.org/ child-rights-convention/convention-text-childrens-v ersion

18. ReliefWeb. Informing humanitarians worldwide. Accessed March 6, 2021. https://reliefweb.int

19. Tahghighi Sharabian F, Ziaee V. Management of Childhood Rheumatic Diseases During the COVID-19 Pandemic: A Survey on Parental Approaches and Involvements in the Treatment Procedure. Iran J Pediatr. 2021;31(2):e108735. doi:10.5812/ijp.108735

20. Fazil H. Challenges Faced by Parents of Children with Intellectual Disabilities studying in Government and Private Schools during Lockdown Due to COVID-19 in Lahore. PSSR. 2020;4(III):1079-1091. do i:10.35484/pssr.2020(4-iii)78 
21. Al Agha AE, Alharbi RS, Almohammadi OA, Yousef SY, Sulimani AE, Alaama RA. Impact of COVID-19 lockdown on glycemic control in children and adolescents. Saudi Med J. 2021;42(1):44-48. doi:1 $\underline{0.15537 / \mathrm{smj} .2021 .1 .25620}$

22. Bin Muammar NF, Ajeebi AA, Aladwany AL, Yousif A, Alharthy N, Phillip W. Factors associated with delayed child vaccine during coronavirus disease-2019 pandemic. SJEMed. 2021;2(1):18-25. do i:10.24911/sjemed/72-1603445943

23. Almoosa A, Alhamoud H, Alkhalaf AB, et al. Impact of Coronavirus Disease 2019 (COVID-19) pandemic on routine pediatric vaccination in Eastern Region, Saudi Arabia. J Vaccines Vaccin. 2020;11(435).

24. Alsuhaibani M, Alaqeel A. Impact of the COVID-19 Pandemic on Routine Childhood Immunization in Saudi Arabia. Vaccines. 2020;8(4):581. doi:10.3390/vaccines8040581

25. Araby EM, Emadeldin EM, Zakaria HM. COVID-19 Quarantine Measures and Its Impact on Pattern of Life of School Children. The Egyptian Journal of Hospital Medicine. 2021;82(2):217-224. doi:10.21608/e ihm.2021.140450

26. Hashem SA, El Refay AS, Mostafa HH, Kamel IH, Sherif LS. Impact of Coronavirus Disease-19 Lockdown on Egyptian Children and Adolescents: Dietary Pattern Changes Health Risk. Open Access Maced J Med Sci. 2020;8(T1):561-569. doi:10.3889/oa mims.2020.5249

27. Abdelrahman M, Al-Adwan D, Hasan Y. Impact of Social Distancing on the Mental Health of Parents and Children in Qatar. Int J Ment Health Addiction. Published online June 7, 2021. doi:10.1007/s11469-02 1-00555-6

28. Andejany N, Qutah K, Alwajeeh S, Msallam R, Alyamani D. Parent Child Relationship During COVID-19 in Saudi Arabia. Research Square. Published online October 26, 2020. doi:10.21203/r s.3.rs-93850/v1

29. Khalid IS, Akram S. Polio Resurgence in Pakistan: Challenges and policy options. :12.

30. Martinez M, Akbar IE, Wadood MZ, Shukla H, Jorba J, Ehrhardt D. Progress Toward Poliomyelitis Eradication - Afghanistan, January 2019-July 2020. MMWR Morb Mortal Wkly Rep. 2020;69(40):1464-1468. doi:10.15585/mmwr.mm6940 a3
31. Alrabiaah AA, Alshaer AH, Estrella SMC, et al. Effects of the Coronavirus disease 2019 pandemic on routine pediatric immunization coverage rates at the main University Hospital in Saudi Arabia. Saudi Med J. 2020;41(11):1197-1203. doi:10.15537/smj.2020.11.25 $\underline{457}$

32. Abd Al Gawad R, Hanafy R. The Impact of COVID-19 Pandemic on the Utilization of Pediatric Dental Care of Egyptian Children: A Retrospective Study. Egyptian Dental Journal. 2021;67(1):131-137. $\underline{\mathrm{d}}$ oi:10.21608/edj.2020.52574.1396

33. Hasan S, Kalsoom Q. Children and Adolescents' Affect during Lock-down for Covid-19: Case of Pakistan. Published online September 28, 2020. doi:1 $\underline{0.31124 / \text { advance.12982469.v1 }}$

34. Anahita KK, Mahsa AM. Motherhood and Home Quarantine: Exploring the Experiences of Iranian Mothers in Caring for their Children During the COVID-19 Outbreak. Journal of Client-Centered Nursing Care. 2020;6(2):87-96.

35. ReliefWeb. UNICEF Yemen Country Office Humanitarian Situation Report (Reporting Period: 1 31 March 2020). Accessed February 18, 2021. https://r eliefweb.int/report/yemen/unicef-yemen-country-offi ce-humanitarian-situation-report-reporting-perio d-1-31-march

36. ReliefWeb. Afghanistan: COVID-19 Multi-Sectoral Response Operational Situation Report, 14 January 2021. Accessed March 9, 2021. https://reliefweb.int/re port/afghanistan/afghanistan-covid-19-multi-sectora l-response-operational-situation-report-14

37. ReliefWeb. Afghanistan: COVID-19 Multi-Sectoral Response Operational Situation Report, 13 May 2020. Accessed January 17, 2021. https://reliefweb.int/repor t/afghanistan/afghanistan-covid-19-multi-sectoral-re sponse-operational-situation-report-13-may

38. ReliefWeb. Afghanistan: COVID-19 Multi-Sectoral Response Operational Situation Report, 15 October 2020. Accessed February 19, 2021. https://reliefweb.in t/report/afghanistan/afghanistan-covid-19-multi-sect oral-response-operational-situation-report-15

39. ReliefWeb. Afghanistan: COVID-19 Multi-Sectoral Response Operational Situation Report, 3 June 2020. Accessed February 18, 2021. https://reliefweb.int/repo rt/afghanistan/afghanistan-covid-19-multi-sectoral-r esponse-operational-situation-report-3-june

40. ReliefWeb. Afghanistan: Strategic Situation Report: COVID-19, No. 71 (27 August 2020). Accessed January 17, 2021. https://reliefweb.int/report/afghani stan/afghanistan-strategic-situation-report-covid-1 9-no-71-27-august-2020 
41. ReliefWeb. Iraq: Protection Monitoring of Refugees in Response to COVID-19 Round 2 (October 2020). Accessed February 18, 2021. https://reliefweb.i nt/report/iraq/iraq-protection-monitoring-refugees-r esponse-covid-19-round-2-october-2020

42. ReliefWeb. Pakistan: End-year 2020 Situation Report (Non-COVID-19 Response) - Reporting Period: 1st January to 31st December 2020. Accessed February 15, 2021. https://reliefweb.int/report/pakist an/pakistan-end-year-2020-situation-report-non-cov id-19-response-reporting-period-1st

43. ReliefWeb. State of Palestine : Humanitarian Situation Report, End of Year 2020 - occupied Palestinian territory. Accessed February 18, 2021. htt ps://reliefweb.int/report/occupied-palestinian-territo ry/state-palestine-humanitarian-situation-report-en d-year-2020

44. ReliefWeb. State of Palestine: Situation Report No. 1, January - March 2020 - occupied Palestinian territory. ReliefWeb. Accessed January 23, 2021. http s://reliefweb.int/report/occupied-palestinian-territor $\mathrm{y} /$ state-palestine-situation-report-no-1-january-mar ch-2020

45. ReliefWeb. Sudan Situation Report, 9 Nov 2020. Accessed February 19, 2021. https://reliefweb.int/repo rt/sudan/sudan-situation-report-9-nov-2020-enar

46. ReliefWeb. UNFPA Sudan Response and Needs for COVID19, March to June 2020. Accessed February 19, 2021. https://reliefweb.int/report/sudan/unfpa-suda n-response-and-needs-covid19-march-june-2020

47. ReliefWeb. UNHCR Lebanon COVID-19 Update: Overview 2020. Accessed February 18, 2021. https://re liefweb.int/report/lebanon/unhcr-lebanon-covid-19-u pdate-overview-2020

48. ReliefWeb. UNICEF Afghanistan Humanitarian Situation Report No. 1: Mid-Year 2020. Accessed January 17, 2021. https://reliefweb.int/report/afghani stan/unicef-afghanistan-humanitarian-situation-rep ort-no-1-mid-year-2020

49. ReliefWeb. UNICEF Sudan Humanitarian Situation Report, First Quarter 2020. Accessed February 19, 2021. https://reliefweb.int/report/sudan/unicef-suda n-humanitarian-situation-report-first-quarter-2020

50. ReliefWeb. UNICEF Whole of Syria Humanitarian Situation Report - End-of-year 2020. Accessed February 19, 2021. https://reliefweb.int/report/syria n-arab-republic/unicef-whole-syria-humanitarian-sit uation-report-end-year-2020
51. ReliefWeb. UNICEF Whole of Syria Humanitarian Situation Report: January - June 2020. Accessed March 9, 2021. https://reliefweb.int/report/syrian-ara b-republic/unicef-whole-syria-humanitarian-situatio n-report-january-june-2020

52. ReliefWeb. UNHCR Operational Update, 16 July 2020 - Yemen. Accessed February 18, 2021. https://rel iefweb.int/report/yemen/yemen-unhcr-operational-u pdate-16-july-2020

53. ReliefWeb. OCHA Yemen Situation Report - 9 Dec 2020. Accessed January 26, 2021. https://reliefweb.in t/sites/reliefweb.int/files/resources/Situation\%20Rep ort\%20-\%20Yemen\%20-\%209\%20Dec\%202020.pdf

54. ReliefWeb. Whole of Syria Nutrition Cluster Sector Brief - Nutrition Situation in North West Syria (October 2020). Accessed March 10, 2021. https://relie fweb.int/report/syrian-arab-republic/whole-syria-nut rition-cluster-sector-brief-nutrition-situation-north

55. ReliefWeb. UNICEF Somalia Humanitarian Situation Report No. 11, reporting period 1 to 30 November 2020 - Somalia. Accessed March 10, 2021. https://reliefweb.int/report/somalia/unicef-somalia-h umanitarian-situation-report-no-11-reporting-perio d-1-30-november

56. ReliefWeb. Syria - Complex Emergency Fact Sheet \#2, Fiscal Year (FY) 2021. Accessed February 19, 2021. https://reliefweb.int/report/syrian-arab-republic/syri a-complex-emergency-fact-sheet-2-fiscal-year-fy-202 $\underline{1}$

57. ReliefWeb. Child Protection Working Group Lebanon: Monitoring Children's Situation in Lebanon in the first-half of 2020 (September 2020). Accessed January 26, 2021. https://reliefweb.int/report/lebano $\mathrm{n}$ /child-protection-working-group-lebanon-monitori ng-children-s-situation-lebanon-first

58. ReliefWeb. Recent Developments in Northwest Syria - Situation Report No. 17 - As of 13 July 2020. Accessed January 23, 2021. https://reliefweb.int/repor t/syrian-arab-republic/recent-developments-northwe st-syria-situation-report-no-17-13-july-2020

59. ReliefWeb. Recent Developments in Northwest Syria - Situation Report No. 21 - As of 20 October 2020. Accessed January 23, 2021. https://reliefweb.in t/report/syrian-arab-republic/recent-developments-n orthwest-syria-situation-report-no-21-20-october

60. ReliefWeb. Recent Developments in Northwest Syria - Situation Report No. 23 - As of 21 December 2020. Accessed March 10, 2021. https://reliefweb.int/r eport/syrian-arab-republic/recent-developments-nort hwest-syria-situation-report-no-23-21-december 
61. ReliefWeb. UNICEF Libya Country Office

Humanitarian Situation Report No. 3 July -

September 2020. Accessed February 18, 2021. http

s://reliefweb.int/report/libya/unicef-libya-country-off ice-humanitarian-situation-report-no-3-july-septem ber-2020

62. ReliefWeb. Iraq: 2020 Internal Displacement Crisis Humanitarian Situation Report (Reporting Period: 01 January 2020 to 31 March 2020). Accessed February 18, 2021. https://reliefweb.int/report/iraq/ir aq-2020-internal-displacement-crisis-humanitariansituation-report-reporting-period-01

63. ReliefWeb. Recent Developments in Northwest Syria - Flash Update - As of 29 May 2020 - Syrian Arab Republic. Accessed February 18, 2021. https://reliefwe b.int/report/syrian-arab-republic/recent-developmen ts-northwest-syria-flash-update-29-may-2020

64. ReliefWeb. UNICEF Iraq Humanitarian Situation Report (IDP Crisis): Q2/April-June 2020. Accessed February 18, 2021. https://reliefweb.int/report/iraq/u nicef-iraq-humanitarian-situation-report-idp-crisis-q 2april-june-2020

65. ReliefWeb. Recent Developments in Northwest Syria - Situation Report No. 18 - As of 25 July 2020. Accessed January 23, 2021. https://reliefweb.int/repor t/syrian-arab-republic/recent-developments-northwe st-syria-situation-report-no-18-25-july-2020

66. United Nations Children's Fund. Assessment of COVID-19 Impact on Poverty and Vulnerability in Iraq. Accessed January 22, 2021. https://www.unicef.o rg/iraq/reports/assessment-covid-19-impact-povertyand-vulnerability-iraq

67. ReliefWeb. Recent Developments in Northwest Syria - Flash Update - As of 07 August 2020 - Syrian Arab Republic. Accessed March 10, 2021. https://relief web.int/report/syrian-arab-republic/recent-developm ents-northwest-syria-flash-update-07-august-2020

68. ReliefWeb. UNHCR Iraq Protection Monitoring of Refugees in Response to COVID-19. Accessed January 22, 2021. https://reliefweb.int/sites/reliefweb.int/file s/resources/IRO Protection\%20Monitoring_Round\%2 02\%20Analysis_Nov\%202020.pdf

69. ReliefWeb. UNHCR Yemen Operational Update 16 July 2020. Accessed January 23, 2021. https://relief web.int/sites/reliefweb.int/files/resources/77773.pdf

70. ReliefWeb. Syrian Arab Republic: Recent Developments in Northwest Syria - Flash Update - As of 08 May 2020. Accessed January 23, 2021. https://rel iefweb.int/report/syrian-arab-republic/syrian-arab-re public-recent-developments-northwest-syria-flash-u pdate-08
71. ReliefWeb. Recent Developments in Northwest Syria - Situation Report No. 16 - As of 26 June 2020 Syrian Arab Republic. Accessed January 23, 2021. http s://reliefweb.int/report/syrian-arab-republic/recent-d evelopments-northwest-syria-situation-report-no-1 6-26-june-2020

72. United Nations Children's Fund. COVID-19 may push millions more children into child labour - ILO and UNICEF. Accessed March 10, 2021. https://www.u nicef.org/press-releases/covid-19-may-push-million $\underline{\text { s-more-children-child-labour-ilo-and-unicef }}$

73. ReliefWeb. Afghanistan: Weekly Humanitarian Update (28 December 2020 - 3 January 2021). Accessed February 11, 2021. https://reliefweb.int/repo rt/afghanistan/afghanistan-weekly-humanitarian-up date-28-december-2020-3-january-2021

74. World Vision. The assessment of socio-economic impact of COVID-19 on the most vulnerable families in Afghanistan. Accessed February 18, 2021. https://re liefweb.int/sites/reliefweb.int/files/resources/Assessm ent\%20Final\%20for\%20Web\%205.pdf

75. ReliefWeb. Afghanistan: Strategic Situation Report: COVID-19, No. 84 (19 November 2020). Accessed March 19, 2021. https://reliefweb.int/report/ afghanistan/afghanistan-strategic-situation-report-c ovid-19-no-84-19-november-2020

76. ReliefWeb. Afghanistan: COVID-19 Multi-Sectoral Response Operational Situation Report, 12 November 2020. Accessed March 19, 2021. https://reliefweb.int/r eport/afghanistan/afghanistan-covid-19-multi-sector al-response-operational-situation-report-12-0

77. ReliefWeb. Afghanistan: COVID-19 Multi-Sectoral Response Operational Situation Report, 20 December 2020. Accessed March 19, 2021. https://reliefweb.int/r eport/afghanistan/afghanistan-covid-19-multi-sector al-response-operational-situation-report-20-0

78. ReliefWeb. OCHA Humanitarian Bulletin Somalia, August 2020. Accessed January 26, 2021. https://relief web.int/sites/reliefweb.int/files/resources/August\%20 2020\%20humanitarian\%20bulletin-publication.pdf

79. ReliefWeb. UNICEF Somalia Humanitarian Situation Report No. 10 , reporting period 1 - 31 October 2020. Accessed March 19, 2021. https://relief web.int/report/somalia/unicef-somalia-humanitaria n-situation-report-no-10-reporting-period-1-31-octo ber-2020

80. ReliefWeb. UNICEF-WHO Somalia Flash Update Week no. 38, 2020. Accessed January 26, 2021. http s://reliefweb.int/sites/reliefweb.int/files/resources/3 8.\%20Somalia\%20Flash\%20Update.pdf 
81. ReliefWeb. UNICEF-WHO Somalia Flash Update Week no.36, 2020. Accessed January 26, 2021. http s://reliefweb.int/sites/reliefweb.int/files/resources/3 6.\%20Somalia\%20Flash\%20Update.pdf

82. ReliefWeb. Somalia Polio Flash Update: Week 34 2020. Accessed January 26, 2021. https://reliefweb.in t/report/somalia/somalia-polio-flash-update-week-3 4-2020

83. ReliefWeb. Sudan: Vaccine-derived polio outbreak - Flash Update No. 1. Accessed January 26, 2021. http s://reliefweb.int/report/sudan/sudan-vaccine-derive d-polio-outbreak-flash-update-no-1

84. ReliefWeb. UNHCR Sudan Flash Update - Issue No. 7 - 8 September 2020. Accessed January 26, 2021. https://reliefweb.int/report/sudan/unhcr-sudan-flas h-update-issue-no-7-8-september-2020

85. Hassan S, Saviour M, Perkar S, et al. The Impacts of Home Confinement Due To Coronavirus (COVID-19) on Children: A Cross Sectional Survey Study, Mediclinic City Hospital, Dubai, UAE. American Journal of Pediatrics. 2020;6(4).

86. United Nations Children's Fund. MENARO COVID-19 Situation Report No. 5 - for 15-31 May. Accessed September 21, 2020. https://www.unicef.or g/mena/sites/unicef.org.mena/files/2020-06/UNICE F\%20MENARO\%20COVID-19\%20Situation\%20Repor t\%20No.\%205\%20-\%20for\%2015-31\%20May\%20202 $\underline{0 . p d f}$

87. World Bank. MENA Economic Update: How Transparency Can Help the Middle East and North Africa. World Bank. Accessed March 9, 2021. https://w ww.worldbank.org/en/region/mena/publication/men a-economic-update-april-2020-how-transparency-ca n-help-the-middle-east-and-north-africa

88. ReliefWeb. COVID-19 Emergency Response Update \#6.; 2020. Accessed November 4, 2020. https://reliefw eb.int/sites/reliefweb.int/files/resources/76673.pdf

89. World Vision International. 50\% of families in Afghanistan forced to send their children to work during COVID-19 pandemic. Accessed March 10, 2021. https://www.wvi.org/newsroom/afghanistan/5 0-families-afghanistan-forced-send-their-children-w ork-during-covid-19

90. Girls Not Brides. Child Marriage: A Form of Violence Against Children. Accessed October 1, 2020. https://www.girlsnotbrides.org/resource-centre/chil d-marriage-a-form-of-violence-against-children/
91. United Nations Population Fund. COVID-19

impact brief for UNFPA. Accessed October 1, 2020. htt ps://www.unfpa.org/sites/default/files/resource-pdf/C OVID-19_impact_brief_for_UNFPA_24_April_2020_1.p df

92. Plan International. COVID-19 and Child Labour in Lebanon. Accessed October 3, 2020. https://plan-inter national.org/publications/covid-19-and-child-labourlebanon\#download-options

93. Sprang G, Silman M. Posttraumatic Stress Disorder in Parents and Youth After Health-Related Disasters. Disaster Med Public Health Prep. 2013;7(1):105-110. doi:10.1017/dmp.2013.22

94. UN Special Representative of the SecretaryGeneral on Violence Against Children. COVID19 Global solidarity is key to protect children during and after the crisis, as we are all in this together, ensuring no child is left behind. Accessed June 2, 2020. http s://violenceagainstchildren.un.org/news/covid19-glob al-solidarity-key-protect-children-during-and-after-c risis-we-are-all-together

95. Karkour S, Itsubo N. Influence of the Covid-19 Crisis on Global PM2.5 Concentration and Related Health Impacts. Sustainability. 2020;12(13):5297. do i:10.3390/su12135297

96. Liu F, Wang M, Zheng M. Effects of COVID-19 lockdown on global air quality and health. Science of The Total Environment. 2021;755:142533. doi:10.1016/ j.scitotenv.2020.142533

97. Venter ZS, Aunan K, Chowdhury S, Lelieveld J. COVID-19 lockdowns cause global air pollution declines with implications for public health risk. Proc Natl Acad Sci USA. 2020;117(32):18984-18990. doi:1 0.1073/pnas.2006853117

98. Center for International and Regional Studies Georgetown University in Qatar. Air Pollution and COVID-19 in the GCC and the Middle East. Accessed October 27, 2020. https://cirs.georgetown.edu/news-a nalysis/air-pollution-and-covid-19-gcc-and-middle-e ast

99. Khader YS. Air Pollution and Health Outcomes in the Eastern Mediterranean Region: Knowledge and Research Gaps and Need. In: Laher I, ed. Handbook of Healthcare in the Arab World. Springer International Publishing; 2020:1-45. https://doi.org/10.1007/97 8-3-319-74365-3_56-1

100. Abdo N, Khader YS, Abdelrahman M, et al. Respiratory health outcomes and air pollution in the Eastern Mediterranean Region: a systematic review. Rev Environ Health. 2016;31(2):259-280. doi:10.1515/r eveh-2015-0076 
101. Al-Rawas OA, Al-Maniri AA, Al-Riyami BM. Home exposure to Arabian incense (bakhour) and asthma symptoms in children: a community survey in two regions in Oman. BMC Pulm Med. 2009;9(1):23. $\underline{\mathrm{d}}$ oi:10.1186/1471-2466-9-23

102. Abdul Wahab A, Mostafa OA. Arabian incense exposure among Qatari asthmatic children. A possible risk factor. Saudi Med J. 2007;28(3):476-478.

103. Shiva F, Nasiri M, Sadeghi B, Padyab M. Effects of passive smoking on common respiratory symptoms in young children. Acta Paediatr. 2003;92(12):1394-1397. doi:10.1111/j.1651-2227.200 3.tb00821.x

104. Merghani TH, Saeed AM. The relationship between regular second-hand smoke exposure at home and indictors of lung function in healthy school boys in Khartoum. Tob Control. 2013;22(5):315-318. d oi:10.1136/tobaccocontrol-2011-050169

105. Al-Mousawi MSH, Lovel H, Behbehani N, Arifhodzic N, Woodcock A, Custovic A. Asthma and sensitization in a community with low indoor allergen levels and low pet-keeping frequency. $J$ Allergy Clin Immunol. 2004;114(6):1389-1394. doi:1 $\underline{0.1016 / j . j a c i .2004 .09 .005}$

106. El Hajj R, Mrad Nakhlé M, Abboud M, Chalhoub E, Farah W. Health Effects of Lebanese Schools Indoor Pollution (HELSIE) Pilot Study. Environmental Epidemiology. 2019;3:109. doi:10.1097/01.ee9.000060 6908.77360.b5

107. Alqahtani JM, Asaad AM, Awadalla NJ, Mahfouz AA. Environmental Determinants of Bronchial Asthma among Saudi School Children in Southwestern Saudi Arabia. IJERPH. 2017;14(1):22. do i:10.3390/ijerph14010022

108. Etrhuni S, Omar R, Hadid I. Risk factors of acute respiratory infections in children in Tripoli, Libya. Ibnosina J Med Biomed Sci. 2020;12:200-207.

109. Malaeb D, Hallit S, Sacre H, Hallit R, Salameh P. Factors associated with wheezing among Lebanese children: Results of a cross-sectional study.

Allergologia et Immunopathologia. 2020;48(6):523-529. doi:10.1016/j.aller.2020.02.003

110. El-Ghitany EM, Abd El-Salam MM.

Environmental intervention for house dust mite control in childhood bronchial asthma. Environ Health Prev Med. 2012;17(5):377-384. doi:10.1007/s12199-01 1-0263-5

111. Krieger J, Higgins DL. Housing and Health: Time Again for Public Health Action. Am J Public Health. 2002;92(5):758-768. doi:10.2105/ajph.92.5.758
112. Chang A, Schnall AH, Law R, et al. Cleaning and Disinfectant Chemical Exposures and Temporal Associations with COVID-19 - National Poison Data System, United States, January 1, 2020-March 31, 2020. MMWR Morb Mortal Wkly Rep. 2020;69(16):496-498. doi:10.15585/mmwr.mm6916e1

113. Rundle AG, Park Y, Herbstman JB, Kinsey EW, Wang YC. COVID-19-Related School Closings and Risk of Weight Gain Among Children. Obesity. 2020;28(6):1008-1009. doi:10.1002/oby.22813

114. Musaiger AO, Al-Hazzaa HM. Prevalence and risk factors associated with nutrition-related noncommunicable diseases in the Eastern Mediterranean region. Int J Gen Med. 2012;5:199-217. doi:10.2147/ijgm.s29663

115. National Globalnews. Accidental poisonings from cleaning supplies on the rise during COVID-19 outbreak. Accessed June 2, 2020. https://globalnews.c a/news/6905692/coronavirus-cleaning-poisonings/

116. Samprathi M, Jayashree M. Biomarkers in COVID-19: An Up-To-Date Review. Front Pediatr. 2021;8. doi:10.3389/fped.2020.607647

117. Hanif W, Ali O, Shahzad H, et al. Biochemical Markers in COVID-19 in Multan. J Coll Physicians Surg Pak. 2020;30(10):1026-1029. doi:10.29271/jcpsp.202 $\underline{0.10 .1026}$

118. Grimaud M, Starck J, Levy M, et al. Acute myocarditis and multisystem inflammatory emerging disease following SARS-CoV-2 infection in critically ill children. Ann Intensive Care. 2020;10(1). doi:10.118 6/s13613-020-00690-8

119. Ferrari D, Locatelli M, Faraldi M, Lombardi G. Changes in 25- $(\mathrm{OH})$ Vitamin D Levels during the SARS-CoV-2 Outbreak: Lockdown-Related Effects and First-to-Second Wave Difference-An Observational Study from Northern Italy. Biology. 2021;10(3):237. do i:10.3390/biology10030237

120. Abukabda AB, Razzaque MS. COVID-19 pandemic: Impacts of social lockdown on nutritional health and beyond. Adv Hum Biol. 2021;11(3):7.

121. ReliefWeb. Syria Country Office COVID-19 Humanitarian Response Flash Update No. 7 | 1 - 31 August 2020. Accessed January 23, 2021. https://relief web.int/report/syrian-arab-republic/syria-country-off ice-covid-19-humanitarian-response-flash-update-n o-7-1

122. Haddad N, Andrianou XD, Makris KC. A Scoping Review on the Characteristics of Human Exposome Studies. Curr Pollution Rep. 2019;5(4):378-393. doi:1 $\underline{0.1007 / \mathrm{s} 40726-019-00130-7}$ 
123. United Nations Sustainable Development. About the Sustainable Development Goals. Accessed June 4, 2020. https://www.un.org/sustainabledevelopment/su stainable-development-goals/ 